\title{
ESPECIAÇÃO DO COBRE NA BAÍA DE LUANDA USANDO TÉCNICAS ELECTROQUÍMICAS
}

\author{
A. LEITÃO ${ }^{1}$, A. SANTOS ${ }^{1}$ e R. BOAVENTURA ${ }^{2}$ \\ ${ }^{1}$ Universidade Agostinho Neto, Faculdade de Engenharia, Laboratório de Engenharia da \\ Separação, Reacção e Ambiente (LESRA), Avenida Ho Chi Min n ${ }^{\circ}$ 201, Luanda, Angola \\ ${ }^{2}$ Universidade do Porto, Faculdade de Engenharia, Laboratory of Separation and Reaction \\ Engineering (LSRE), Rua Dr. Roberto Frias, 4200-465 Porto, Portugal \\ E-mail para contacto: anabela.leitao@yahoo.com
}

\begin{abstract}
RESUMO - A especiação é definida como a distribuição dum elemento entre diferentes formas químicas numa amostra. Neste trabalho é apresentado o estudo da especiação do cobre em amostras de água e de sedimento da baía de Luanda. A análise da especiação do cobre, com recurso à voltametria de redissolução anódica, permitiu quantificar as concentrações do cobre ambiental inorgânico, orgânico lábil e orgânico inerte e determinar os parâmetros de complexação do metal com os ligandos orgânicos naturais do meio aquático. A partir dos resultados obtidos pode observar-se que todo o cobre ambiental forma complexos orgânicos inertes com os ligandos do meio. Na água filtrada, os colóides contabilizados como espécies dissolvidas são os principais responsáveis pela complexação do cobre, dominando em simultâneo duas classes de ligandos de cobre, "muito fortes" $(\log K>11)$ e "fortes a moderadamente fortes" $(8<\log K<11)$. $\mathrm{Na}$ água tal e qual e na suspensão do sedimento, verifica-se que a especiação do cobre é dominada por três classes de ligandos orgânicos, como é reportado na literatura, as duas já referidas e a classe de ligandos "moderadamente fortes a fracos" $(5<\log K<8)$.
\end{abstract}

\section{INTRODUÇÃO}

As zonas costeiras (estuários, baías, golfos, etc.) foram, desde sempre, locais privilegiados para a fixação de populações devido aos inúmeros recursos que possuem e têm vindo a ser intensivamente usadas para descargas de esgotos e efluentes industriais. Estes despejos, sem tratamento prévio ou sem tratamento adequado, são uma fonte de poluentes, como matéria orgânica, nutrientes (azoto e fósforo), metais pesados e substâncias refractárias. Os iões metálicos quando lançados num ambiente aquático têm tendência a combinar-se rapidamente com ligandos doadores de electrões distribuídos entre as fases dissolvida e particulada (Ciffroy et al., 2003). A distribuição dos metais entre as fases dissolvida e particulada depende da afinidade física e química do metal dissolvido para as partículas em suspensão. As partículas orgânicas são as que apresentam maior poder de fixação. Na fase dissolvida, os metais podem co-existir em quatro formas químicas (Kozelka e Bruland, 1998): (i) livre (catião hidratado, lábil), que corresponde apenas a uma pequena fracção da totalidade do metal dissolvido; (ii) complexado com ligandos inorgânicos; (iii) complexado com ligandos orgânicos simples para formar espécies lábeis; e (iv) complexado com ligandos macromoleculares ou colóides, dando lugar a complexos inertes. Na fase particulada, os 
metais encontram-se: (i) adsorvidos ou incorporados na matéria orgânica ou inorgânica em suspensão; e (ii) adsorvidos ou incorporados nos sedimentos.

A especiação consiste na identificação e quantificação das várias formas de um mesmo elemento presente numa amostra a ser analisada (Kotas e Stasicka, 2000). A especiação de metais vestigiais é essencial no estudo da química das águas naturais porque propriedades tão importantes como a toxicidade, biodisponibilidade, bioacumulação, biodegradação e mobilidade dos metais dependem da forma química, concentração, estabilidade e cinética das espécies envolvidas (Vasconcelos e Leal, 1997; Guéguen et al., 2004). Embora a relação entre especiação e biodisponibilidade seja complexa, o metal presente como ião livre, lipossolúvel ou na forma de complexos fracos capazes de se dissociarem, é geralmente mais biodisponível do que o metal incorporado em complexos fortes ou adsorvido em coloides e/ou matéria particulada (Markich et al., 2001; Salam, 2003; Guéguen et al., 2004). Muitos estudos de toxicidade de metais pesados em peixes e outros organismos aquáticos mostraram que o metal na forma iónica livre (hidratada) é mais tóxico (Hudson, 1998). Apesar das medidas legislativas ambientais serem ainda elaboradas com base na concentração total de metal, reconhece-se cada vez mais a importância da especiação para tomada de decisões mais eficazes. Entre as técnicas analíticas actualmente disponíveis, a voltametria de redissolução anódica (VRA, ou ASV em inglês) tem sido uma das mais usadas na identificação e quantificação das várias formas de metais pesados em sistemas aquáticos (Mota et al., 2005).

A Baía de Luanda tem servido como corpo receptor de águas residuais e efluentes industriais sem tratamento, de uma parte da cidade de Luanda, durante décadas. Este facto justificou a realização de uma investigação experimental sobre a qualidade da água, das partículas em suspensão e dos sedimentos colhidos em diferentes pontos da baía de Luanda, que incluiu estudos de distribuição dos metais pesados cádmio, chumbo, cobre e zinco nesses compartimentos ambientais (Santos, 2012). O objectivo deste trabalho é apresentar o estudo da especiação do cobre em amostras de água e de sedimento colhidas num dos pontos de amostragem na vizinhança dum colector de descarga de esgoto. A análise da especiação do cobre, com recurso à voltametria de redissolução anódica, permitiu quantificar as concentrações do cobre ambiental inorgânico, orgânico lábil e orgânico inerte e determinar os parâmetros de complexação do metal com os ligandos orgânicos naturais do meio aquático.

\section{TEORIA}

O modelo de Langmuir derivado para descrever matematicamente o equilíbrio de adsorção de um soluto na superfície de um sólido é também usado para descrever o equilíbrio da complexação dum metal com ligandos orgânicos (Muller, 1996; Bruland et al., 2000).

A interpretação de dados de titulação para cobre em ambientes marinhos semelhantes ao deste trabalho indicam a complexação do metal por três classes de ligandos orgânicos (Kozelka e Bruland, 1998). Admitindo dois tipos de ligandos para o metal, com constantes de estabilidade condicionais referidas ao metal inorgânico $K_{1}$ e $K_{2}$, a relação entre as concentrações do metal ligado $\left(C_{M L}\right)$ e do metal inorgânico $\left(C^{\prime}{ }_{M}\right)$ é dada por:

$$
C_{M L}=\frac{C_{L T 1} K_{1} C_{M}^{\prime}}{1+K_{1} C_{M}^{\prime}}+\frac{C_{L T 2} K_{2} C_{M}^{\prime}}{1+K_{2} C_{M}^{\prime}}
$$


em que $C_{L T 1}$ e $C_{L T 2}$ representam as concentrações totais de ligandos de cada uma das classes. Se, para além disso, se admitir ainda a existência de um tipo de ligandos que dá origem a complexos irreversíveis, obtém-se:

$$
C_{M L}=C_{L T 1}+\frac{C_{L T 2} K_{2} C_{M}^{\prime}}{1+K_{2} C_{M}^{\prime}}+\frac{C_{L T 3} K_{3} C_{M}^{\prime}}{1+K_{3} C_{M}^{\prime}}
$$

O ajuste das Equações 1 e 2 aos valores de $C^{\prime}{ }_{M}$ e de $C_{M L}$, obtidos a partir dos dados experimentais de titulação, permite seleccionar o melhor modelo e conhecer os respectivos parâmetros complexométricos.

\subsection{Cálculo da concentração do metal inorgânico em solução}

No presente estudo a concentração de metal inorgânico, $C^{\prime}{ }_{M}$, entendida como a soma das concentrações do metal livre e do metal complexado com os ligandos inorgânicos do meio, foi calculada a cada adição do metal a partir da equação:

$$
C^{\prime}{ }_{M}=\frac{I_{p}{ }^{M L}}{S e^{n \Delta E_{p} / 0,025688}}
$$

desenvolvida com base na equação de De Ford e Hume (Botelho, 1998) para um processo controlado por difusão e considerando que só o metal lábil é electroactivo. Na Equação $3 I_{p}{ }^{M L}$ é a intensidade do pico obtido na titulação da amostra, $\Delta E_{p}$ é a diferença entre o valor do potencial do metal na ausência de ligandos (calibração) e o valor do potencial na presença de ligandos, $S$ é o declive da recta de calibração e $n=2$ para o metal em estudo. Os cálculos foram realizados após a titulação com cobre das amostras (água filtrada, água tal e qual, suspensão de sedimento) e do electrólito de suporte $(\mathrm{NaCl})$ ao mesmo $\mathrm{pH}$ e força iónica do meio.

\subsection{Cálculo da concentração do metal ligado aos ligandos orgânicos}

Neste trabalho admite-se que os complexos do metal com os ligandos orgânicos em solução são lábeis, conforme comprovam testes de labilidade realizados, e que os complexos do metal com os ligandos orgânicos adsorvidos nas partículas são inertes.

$\mathrm{Na}$ titulação de soluções (água filtrada, filtrado de suspensão de sedimento) com o padrão metálico, depois de se ter calculado a concentração de metal inorgânico como se mostrou na secção 2.1, obteve-se a concentração de metal ligado aos ligandos orgânicos, abreviadamente designada por $C_{M L}$, a partir de um balanço molar ao metal:

$$
C_{M T}=C_{M}^{\prime}+C_{M L}
$$

onde a concentração total do metal, $C_{M T}$, é conhecida em cada adição do metal ou em cada ponto da titulação.

Na titulação de amostras de água tal e qual ou de suspensão de sedimento, nas quais estão presentes ligandos orgânicos em solução e ligandos orgânicos adsorvidos nas partículas, 
a concentração de metal ligado aos ligandos orgânicos em solução, $C_{M L}{ }^{\text {sol }}$, foi calculada com base na equação:

$$
\frac{D_{M} C_{M}^{\prime}+D_{M L}{ }^{\text {sol }} C_{M L}{ }^{\text {sol }}}{C^{\prime}{ }_{M}+C_{M L}{ }^{\text {sol }}}=D_{M}\left[\frac{i_{p}{ }^{M L}}{S\left(C^{\prime}{ }_{M}+C_{M L}{ }^{s o l}\right)}\right]^{1 / r}
$$

Tendo em conta que

$$
D_{M L}^{\text {sol }}=D_{M}\left(\frac{S_{1}}{S}\right)^{1 / r}
$$

em que $D_{M L}{ }^{\text {sol }}$ é o coeficiente de difusão do metal complexado com os ligandos orgânicos em solução, $D_{M}$ é o coeficiente de difusão do metal simples, $S_{l}$ é o declive da curva no início da titulação da amostra na ausência de sólidos e $r=0,5$ para difusão linear (Botelho, 1998), substituindo este resultado na Equação 5 resulta:

$$
\frac{C^{\prime}{ }_{M}+\left(S_{1} / S\right)^{2} C_{M L}{ }^{\text {sol }}}{C^{\prime}{ }_{M}+C_{M L}{ }^{\text {sol }}}=\left[\frac{i_{p}{ }^{M L}}{S\left(C^{\prime}{ }_{M}+C_{M L}{ }^{\text {sol }}\right)}\right]^{2}
$$

a partir da qual se calculou $C_{M L}^{\text {sol }}$ depois de se ter obtido a concentração de metal inorgânico conforme descrito na secção anterior.

A concentração de metal ligado aos ligandos orgânicos adsorvidos no sedimento, $C_{M L}{ }^{\text {part }}$, foi calculada a partir do balanço molar ao metal:

$$
C_{M T}=C_{M}^{\prime}+C_{M L}^{\text {sol }}+C_{M L}^{\text {part }}
$$

\section{PARTE EXPERIMENTAL}

Em diferentes pontos de amostragem foram colhidas amostras de água superficial $(0,1$ a $0,5 \mathrm{~m}$ abaixo da superfície da água) e de sedimentos (3 a $5 \mathrm{~cm}$ abaixo da interface água/sedimento). Alguns parâmetros físico-químicos como o pH, condutividade, oxigénio dissolvido e potencial redox foram medidos no local. No laboratório, uma porção da água tal e qual foi filtrada (membrana de $0,45 \mu \mathrm{m}$ ), os sedimentos foram secos por liofilização e foi realizada uma caracterização físico-química das amostras. Neste estudo foi usada a fracção fina $(<63 \mu \mathrm{m})$ dos sedimentos. As titulações voltamétricas com cobre de amostras de água tal e qual, filtrada e de suspensões do sedimento em electrólito de suporte $(\mathrm{NaCl})$, com a mesma força iónica e $\mathrm{pH}$ do meio, foram realizadas num posto polarográfico $663 \mathrm{VA}$ (Metrohm) ligado, através de uma interface, a um potenciostato/galvanostato Autolab PGSTAT12 (EcoChemie). As titulações foram efectuadas com o eléctrodo de mercúrio de gota suspensa. A técnica voltamétrica usada foi a voltametria de redissolução anódica diferencial com impulsos (VRADI). Na etapa de deposição, foi usado um tempo de deposição de $480 \mathrm{~s}$, sob agitação de $1000 \mathrm{rpm}$, a um potencial de $-1000 \mathrm{mV}$. Esta etapa foi seguida de um período de repouso (sem agitação) de $30 \mathrm{~s}$. Na etapa de oxidação, fez-se um varrimento do potencial para valores mais positivos a uma velocidade de $5 \mathrm{mV} / \mathrm{s}$ e foi registado o voltamograma. Após cada adição de padrão metálico à célula polarográfica contendo a amostra, aguardou-se um tempo de 30 
min, antes da etapa de deposição, para dar lugar à complexação do ião metálico com os ligandos orgânicos eventualmente presentes na amostra. Seguidamente, as etapas de deposição, repouso e oxidação foram repetidas até à obtenção de dois picos com a mesma altura (intensidade), largura a meia altura e potencial em registos sucessivos (Santos, 2012).

\section{RESULTADOS E DISCUSSÃO}

Nas titulações de suspensões de sedimentos notou-se o aparecimento de dois picos, um anódico e outro catódico, como referem alguns autores (Boussemart et al., 1993). Segundo estes autores, a matéria orgânica pode conter ligandos L' e L. Os ligandos L complexam o $\mathrm{Cu}$ (II) e são responsáveis pela capacidade complexométrica. Os ligandos L', adsorvidos sobre a gota de mercúrio, complexam o $\mathrm{Cu}$ (I) resultante da dissociação do $\mathrm{Cu}$ (II) na presença de cloretos e o composto $\mathrm{Cu}(\mathrm{I}) \mathrm{L}^{\prime}$ ads é o responsável pelo aparecimento do pico anódico durante a etapa de oxidação. Este composto pode ser reduzido e removido da superfície da gota de mercúrio durante o período de deposição a potenciais mais negativos do que $-600 \mathrm{mV}$ e a tempos de deposição superiores a 2 minutos (Boussemart et al., 1993). Uma vez que o pico anódico se deve à oxidação de uma camada adsorvida, está por conseguinte limitado pela saturação da gota de mercúrio com $\mathrm{Cu}(\mathrm{I}) \mathrm{L}^{\prime}$ ads, ou pela concentração dos ligandos $\mathrm{L}^{\prime} \mathrm{em}$ solução se for demasiado baixa para alcançar a saturação da gota. No presente trabalho foram realizadas titulações voltamétricas a potenciais mais negativos do que $-600 \mathrm{mV}$ e a vários tempos de deposição $(60,120,240$ e 480 s). A Figura 1 mostra que o pico catódico só aparece quando o pico anódico atinge o patamar (saturação da gota de mercúrio com o composto responsável por este pico) e que o pico catódico aparece mais cedo (a menores adições de cobre) a tempos de deposição maiores. Assim, os parâmetros complexométricos dos ligandos $\mathrm{L}$ foram determinados ao potencial de deposição de $-1000 \mathrm{mV}$ e ao tempo de deposição de $480 \mathrm{~s}$, descontando o metal adicionado até ao aparecimento do pico catódico. Nas titulações de água tal e qual, água filtrada e filtrado duma réplica da suspensão de sedimento apareceu apenas o pico catódico.

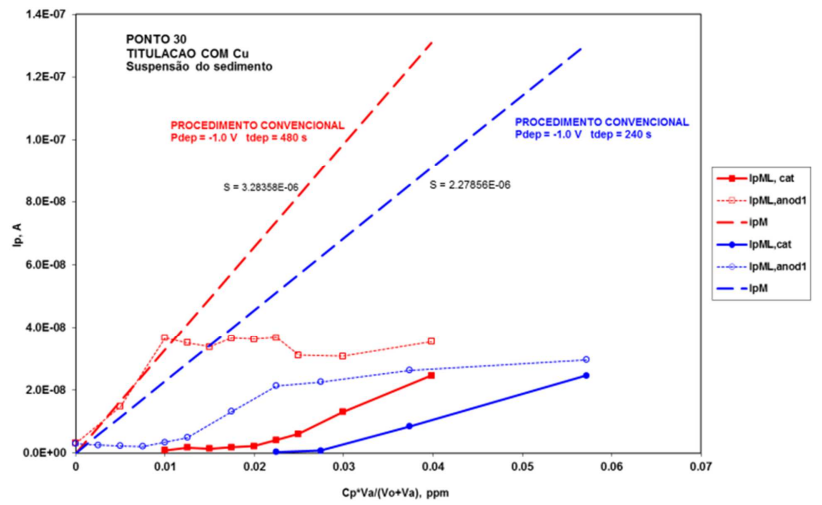

Figura 1 - Titulação da suspensão do sedimento.

A Figura 2 mostra as curvas de titulação de diferentes amostras obtidas num intervalo de concentração de cobre adicionado de $10^{-8}$ a $10^{-6} \mathrm{M}$, assim como a curva da titulação do electrólito de suporte com metal para calibração. Os valores da intensidade e da variação do potencial de pico referem-se ao pico catódico. Verificou-se a ausência de sinal voltamétrico antes da titulação das amostras de água tal e qual e filtrada, indicando que o cobre ambiental se encontra totalmente bio-indisponível. A presença de matéria orgânica coloidal na água 
filtrada permite explicar a formação de complexos muito fortes ou inertes em solução. A existência de zonas com diferentes declives nas curvas de titulação (intensidade do pico em função do cobre adicionado) da água tal e qual, água filtrada e suspensão de sedimento indicia, logo à partida, a existência de pelo menos duas classes de ligandos orgânicos nestes compartimentos ambientais. Na curva de titulação do filtrado duma réplica da suspensão de sedimento não é perceptível nenhuma distinção de zonas, uma vez que desde o início até ao fim da titulação o declive é próximo do da curva de calibração, pressupondo a existência de apenas uma classe de ligandos.
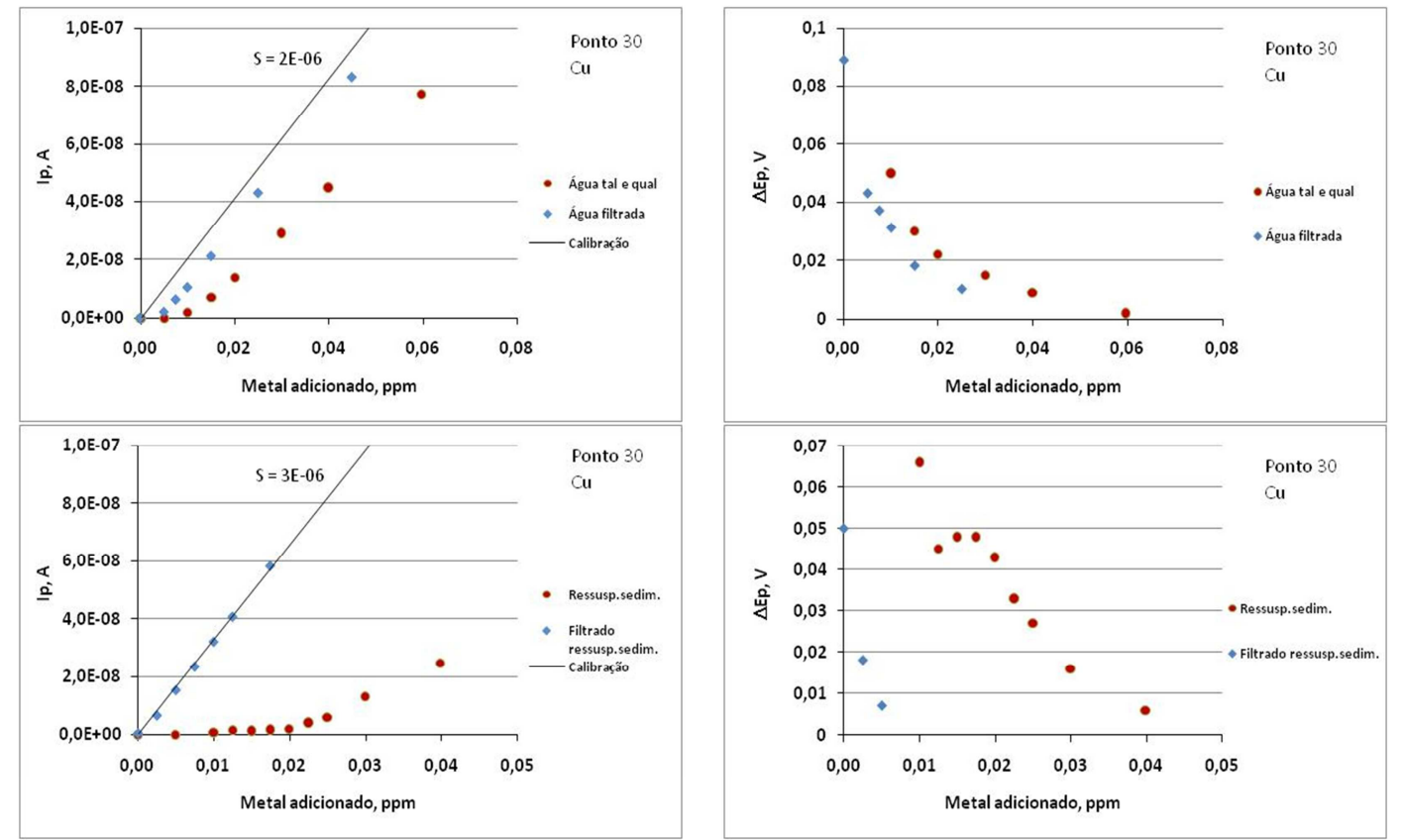

Figura 2 - Intensidade do pico e variação de potencial em função da quantidade de $\mathrm{Cu}$ adicionado na titulação de diferentes amostras.

A partir dos valores medidos da intensidade e da variação do potencial de pico para diferentes valores da concentração de cobre adicionado foram calculados os valores das concentrações de metal inorgânico e de metal ligado a ligandos orgânicos, assim como os parâmetros dos complexos orgânicos formados, de acordo com a metodologia descrita atrás.

A distribuição de cobre no meio aquático é apresentada na Tabela 1. Nas amostras de água tal e qual, água filtrada e suspensão de sedimento todo o cobre inicialmente presente no meio forma complexos orgânicos inertes com os ligandos do meio.

Tabela 1 - Distribuição de cobre no meio aquático

\begin{tabular}{|c|c|c|c|c|c|}
\hline $\begin{array}{l}\text { Ponto de } \\
\text { Amostragem }\end{array}$ & Amostra & $\begin{array}{c}\mathrm{C}_{\mathrm{o}} \\
(\mathrm{nM})\end{array}$ & $\begin{array}{c}\text { Metal } \\
\text { Inorgânico } \\
(\%)\end{array}$ & $\begin{array}{c}\text { Metal Orgânico } \\
\text { Lábil } \\
(\%)\end{array}$ & $\begin{array}{c}\text { Metal Orgânico } \\
\text { Inerte } \\
(\%)\end{array}$ \\
\hline \multicolumn{6}{|l|}{30} \\
\hline & água tal e qual & 105,40 & 0,00 & 0,00 & 100 \\
\hline & água filtrada & 25,33 & 0,00 & - & 100 \\
\hline & suspensão de sedimento & 35,88 & 0,00 & 0,00 & 100 \\
\hline
\end{tabular}


Na Tabela 2 mostram-se os parâmetros de complexação para o cobre. Constata-se que a concentração total de ligandos é maior que a concentração de metal ambiental, $\mathrm{C}_{0}$, em todos os compartimentos ambientais.

Tabela 2 - Parâmetros de complexação para o cobre

\begin{tabular}{lcccccc}
\hline Amostra & $\mathrm{C}_{0}, \mathrm{M}$ & $\mathrm{L}_{\text {iner }}{ }^{*}, \mathrm{M}$ & $\mathrm{L}_{2}, \mathrm{M}$ & $\log \mathrm{K}_{2}$ & $\mathrm{~L}_{3}, \mathrm{M}$ & $\log \mathrm{K}_{3}$ \\
\hline PONTO 30 & & & & & & \\
Água filtrada & $2,533 \times 10^{-8}$ & --- & $9,843 \times 10^{-8}$ & 12,37 & $1,705 \times 10^{-7}$ & 8,01 \\
Água tal e qual & $1,054 \times 10^{-7}$ & $1,447 \times 10^{-7}$ & $1,349 \times 10^{-7}$ & 8,31 & $8,302 \times 10^{-7}$ & 5,67 \\
Sólidos & --- & $1,447 \times 10^{-7}$ & $1,448 \times 10^{-7}$ & 9,96 & $2,287 \times 10^{-7}$ & 6,72 \\
Filtrado de sedimento & $2,056 \times 10^{-9}$ & --- & $3,906 \times 10^{-8}$ & 8,92 & --- & --- \\
Sedimento & $3,588 \times 10^{-8}$ & $3,588 \times 10^{-8}$ & $2,449 \times 10^{-7}$ & 9,69 & $4,204 \times 10^{-7}$ & 6,86
\end{tabular}

* Estão designados por $\mathrm{L}_{\text {iner }}$ os ligandos que formam complexos inertes com o metal

A ordem encontrada de concentração de ligandos para complexar o cobre nos vários compartimentos ambientais é a seguinte: água tal e qual > sólidos da suspensão de sedimento > água filtrada > filtrado da suspensão de sedimento. O cobre ambiental na água tal e qual e na suspensão de sedimento encontra-se todo no sólido, formando complexos inertes com os ligandos do sólido. Também todo o cobre presente na água filtrada forma com os ligandos orgânicos existentes no meio complexos muito fortes $(\log K>12)$ pelo que este metal não representa perigo ambiental. Em relação à força dos ligandos, estes são do mesmo tipo nos sólidos do sedimento e nos sólidos da água tal e qual e são mais fracos no filtrado de sedimento do que na água filtrada.

Nesta investigação os complexos do metal com os ligandos orgânicos do meio foram classificados em quatro grandes grupos ou categorias de acordo com o valor da constante de estabilidade: (i) muito fortes, $\log \mathrm{K}>11$; (ii) fortes a moderadamente fortes, $8<\log \mathrm{K}<11$; (iii) moderadamente fortes a fracos, $5<\log \mathrm{K}<8$; e (iv) muito fracos, $\log \mathrm{K}<5$. Na água tal e qual e na suspensão do sedimento verifica-se que a especiação do cobre é dominada pelas três primeiras classes de ligandos orgânicos, tal como é reportado na literatura para a especiação do cobre nas águas naturais (Kozelka e Bruland, 1998). Na água filtrada dominam as duas primeiras classes de ligandos de cobre e no filtrado duma réplica da suspensão do sedimento encontra-se apenas a classe de ligandos que dá origem a complexos fortes a moderadamente fortes com o cobre.

\section{CONCLUSÕES}

Pretendeu-se com este trabalho dar um contributo para a investigação da especiação do cobre em meios marinhos em geral e na Baía de Luanda em particular. Tal como é reportado na literatura, na água tal e qual e em suspensões do sedimento a especiação do cobre foi dominada por três classes de ligandos complexantes do metal, nomeadamente, "muito fortes", "fortes a moderadamente fortes" e "moderadamente fortes a fracos", encontrando-se todo o cobre ambiental no sólido formando complexos inertes com os ligandos orgânicos do sólido. Pode-se concluir que o cobre na Baía de Luanda não representa um risco eminente para as comunidades aquáticas. 


\section{REFERÊNCIAS BIBLIOGRÁFICAS}

BOTELHO, C. Especiação de iões metálicos em três estações do Rio Este em diferentes épocas do ano. Tese de Doutoramento, Faculdade de Engenharia, Universidade do Porto, 1998.

BOUSSEMART, M.; MENARGUES, L.; BENAIM, J-Y. Anodic stripping voltammetry of copper in natural waters: a qualitative approach to the additional peak(s) occurrence. Electroanal., v. 5, p. 125-133, 1993.

BRULAND, W.; RUE, E.; DONAT, J.; SKRABAL, S.; MOFFETT, J. Intercomparison of voltammetric techniques to determine the chemical speciation of dissolved copper in a coastal seawater sample. Anal. Chim. Acta, v. 405, p. 99-113, 2000.

CIFFROY, P.; GARNIER, J-M.; BENYAHYA, L. Kinetic partitioning of Co, Mn, Cs, Fe, $\mathrm{Ag}, \mathrm{Zn}$ and $\mathrm{Cd}$ in fresh waters (Loire) mixed with brackish waters (Loire estuary): experimental and modelling approaches. Mar. Pollut. Bull., v. 46, p. 626-641, 2003.

GUÉGUEN, C.; GILBIN, R.; PARDOS, M.; DOMINIK, J. Water toxicity and metal contamination assessment of a polluted river: the upper Vistula River (Poland). Appl. Geochem., v. 19, p. 153-162, 2004.

HUDSON, R. Which aqueous species control the rates of trace metal uptake by aquatic biota? Observations and predictions of non-equilibrium effects. Sci. Total Environ., v. 219, p. 95-115, 1998.

KOTAS, J.; STASICKA, Z. Chromium occurrence in the environment and methods for its speciation. Environ. Pollut., v. 107, p. 263-283, 2000.

KOZELKA, P.; BRULAND, K. Chemical speciation of dissolved $\mathrm{Cu}, \mathrm{Zn}, \mathrm{Cd}, \mathrm{Pb}$ in Narragansett Bay, Rhode Island. Mar. Chem., v. 60, p. 267-282, 1998.

MARKICH, S.; BROWN, P.; BATLEY, G.; APTE, S.; STAUBER, J. Incorporation of metal speciation and bioavailability into water quality guidelines for protecting aquatic ecosystems. Australas. J. Ecotoxicology, v. 7, p. 109-122, 2001.

MOTA, A.; CRUZ, P.; VILHENA, C.; GONÇALVES, M. Influence of the sediment on lead speciation in the Tagus estuary. Water Res., v. 39, p. 1451-1460, 2005.

MULLER, F. Interactions of copper, lead, and cadmium with the dissolved, colloidal and particulate components of estuarine and coastal waters. Mar. Chem., v. 52, p. 245-268, 1996.

SALAM, M. Determination of $C d(I I), C u(I I), Z n$ (II) and $\mathrm{Pb}$ (II) speciation in aqueous solutions by electrochemical techniques. Thesis submitted in partial fulfilment of the requirements for the degree of Master in Science, Carleton University, 2003.

SANTOS, A. Estudo da Qualidade da Água da Baía de Luanda: Distribuição de Metais Pesados na Água, Sólidos Suspensos e Sedimentos. Tese de Doutoramento, Faculdade de Engenharia, Universidade Agostinho Neto, 2012.

VASCONCELOS, M.; LEAL, M. Speciation of $\mathrm{Cu}, \mathrm{Pb}, \mathrm{Cd}$ and $\mathrm{Hg}$ in waters of the Oporto coast in Portugal using pre-concentration in a chelamine resin column. Anal. Chim. Acta, v. 353, p. 189-198, 1997. 